\title{
Transcriptomic Analysis of Porcine Granulosa Cells Overexpressing Retinol Binding Protein 4
}

\author{
Yun Zhao ${ }^{1}$, Chunjin $\mathrm{Li}^{2}$ and $\mathrm{Xu}$ Zhou ${ }^{1, *(1)}$ \\ 1 College of Animal Sciences, Jilin University, Changchun 130062, China \\ 2 Jilin Provincial Key Laboratory of Animal Embryo Engineering, Jilin University, Changchun 130062, China \\ * Correspondence: xzhou65@vip.sina.com
}

Received: 16 May 2019; Accepted: 9 August 2019; Published: 13 August 2019

\begin{abstract}
Retinol binding protein 4 (RBP4), mainly secreted by the liver and adipocytes, is a transporter of vitamin A. RBP4 has been shown to be involved in several pathophysiological processes, such as obesity, insulin resistance, and cardiovascular risk. Reports have indicated the high expression levels of RBP4 in cystic follicles. However, the role of RBP4 in mammalian follicular granulosa cells (GCs) remains largely unknown. To illustrate the molecular pathways associated with the effects of RBP4 on GCs, we used high-throughput sequencing to detect differential gene expression in GCs overexpressing RBP4. A total of 113 differentially expressed genes (DEGs) were identified in RBP4-overexpressing GCs, and they included 71 upregulated and 42 downregulated genes. The differential expressions of the top 10 DEGs were further confirmed by real-time quantitative polymerase chain reaction. Pathway analysis indicated that the DEGs are mostly involved in oxidative phosphorylation, Parkinson's disease, non-alcoholic fatty liver disease, Huntington's disease, cardiac muscle contraction, Alzheimer's disease, fatty acid biosynthesis, AMP-activated protein kinase signaling pathway, and insulin signaling pathway. Genes in these pathways should be useful for future studies on GCs. Altogether, the results of our study establish a framework for understanding the potential functions of RBP4 in porcine GCs.
\end{abstract}

Keywords: granulosa cells (GCs); high-throughput sequencing; pLVX-IRES-ZsGreen vector; retinol binding protein $4(R B P 4)$

\section{Introduction}

Retinols (a metabolite form of vitamin $\mathrm{A}, \mathrm{ROH}$ ) mediate various reproductive processes, such as follicle development, oocyte maturation, early embryogenesis, and steroidogenesis [1-4]. Retinol binding protein 4 (RBP4) is an adipokine belonging to the lipocalin family of proteins; it plays a role in the transport of retinols from liver and adipose tissues to the blood and other tissues $[5,6]$. The pivotal action of RBP4 is mediated by a plasma membrane receptor stimulated by retinoic acid 6 (STRA6) [7]. RBP4 exerts its function by binding retinols in blood to form a transient RBP4-ROH complex. STRA6 facilitates the dissociation of retinols from the complex and transports them into cells [8]. RBP4, which is involved in retinol metabolism, has also been identified to be associated with numerous metabolic diseases, such as insulin resistance (IR), type 2 diabetes mellitus, obesity, and cardiovascular risk $[9,10]$. RBP4 expression in adipose tissues is regulated by $17-\beta$-estradiol. RBP4 levels in serum are elevated in polycystic ovary syndrome (PCOS) women with obesity [11]. RBP4 can drive ovarian cancer cell migration and proliferation through RhoA/Rock1 and extracellular signal-regulated kinase pathways involving matrix metalloproteinase (MMP) 2 and MMP9 expressions [12].

The roles of RBP4 in reproduction have been supported by accumulating studies. A recent study identified a new single nucleotide polymorphism in RBP4 affecting the production of large litter size of sows [13]. Studies have shown that RBP4 expresses in bovine ovarian cells [14], early vitellogenic 
oocytes of the trout ovary [15], and ovaries of zebrafish [16]. In addition, RBP4 is expressed during the period of pig blastocyst [17], in the gravid endometrium around day 12 of pregnancy of sows [18]. RBP4 has also been found to be a major secretory product of the pig conceptus [19]. Researchers also reported that the most advanced conceptuses secrete the RBP4 necessary for their development [20]. These evidences suggest that RBP4 plays important roles in ovarian, uterine, and conceptus physiology.

Ovarian granulosa cells (GCs) are important somatic cells and play a central role in steroidogenesis, which is critical for female reproduction. The growth and development of GCs are regulated by a complex cell signaling system, which significantly influences follicular development and oocyte maturation. Factors regulating functions of GCs may therefore play important roles in follicular health and female reproduction [21]. The levels of RBP4 and retinols in the fluids of large follicles are higher than those in the fluids of medium or small follicles [14]. The expression of RBP4 can also be detected in ovarian GCs of various species, including pigs [22], mice [23], and cows [14]. Furthermore, our previous studies have detected high concentrations of RBP4 in porcine cystic follicles [22]. A recent study revealed that $R B P 4$ is highly expressed in follicular fluids of large porcine follicles. RBP4 can also increase the expressions of follicle-stimulating hormone receptor (FSHR) and luteinizing hormone receptor ( $L H R)$ in GCs [24]. These data suggest that ovarian RBP4 might be involved in normal ovarian function. However, current available information on the function and regulatory mechanism of RBP4 in GCs is limited. This study aimed to analyze the function of the porcine RBP4 gene using gene overexpression and high-throughput sequencing.

\section{Materials and Methods}

\subsection{Obligatory Ethical Approval}

All experiments in the present study were performed in accordance with the guidelines of the Animal Care and Use Committee of Jilin University Changchun, China (approval number: JLU\#20150903).

\subsection{Cell Culture}

Unless otherwise specified, all the chemicals and reagents were purchased from Takara (Takara, Dalian, China). The 293T cell line (ATCC, CRL-11268; Manassas, VA, USA), which were used to generate lentivirus, were cultured in Dulbecco's Modified Eagle Medium/Ham's F-12 (DMEM/ F12) (Hyclone, Logan, UT, USA) supplemented with 10\% fetal bovine serum (FBS) (Invitrogen, Carlsbad, CA, USA) and $1 \%$ penicillin-streptomycin under humidified atmosphere containing $5 \% \mathrm{CO}_{2}$ at $37^{\circ} \mathrm{C}$

The current study followed the culture procedure of a previous method [25]. Landrace porcine ovaries were collected from pre-pubertal gilts aged 165-180 days from a local slaughterhouse and transported to laboratory within $20 \mathrm{~min}$ in saline at $37^{\circ} \mathrm{C}$. The follicular fluid aspirated from $3-6 \mathrm{~mm}$ follicles was centrifuged at $500 \times g$ for $5 \mathrm{~min}$ and washed thrice with phosphate buffer saline (PBS). The viability of cells before cell culture was assessed by trypan blue exclusion assay. The GCs were seeded at an initial density of $1 \times 10^{6}$ cells $/ \mathrm{mL}$ in six-well plates. The culture medium consisted of DMEM/F12 with $10 \%$ FBS and 1\% penicillin-streptomycin. The cells were incubated under humidified atmosphere containing $5 \% \mathrm{CO}_{2}$ at $37^{\circ} \mathrm{C}$ for $24 \mathrm{~h}$ and then washed with PBS to remove any unattached cells.

\subsection{Plasmid Constructs, Transfection, and Infection}

The primer sequences used for RBP4 amplification containing XhoI and NotI restriction enzyme sites in the forward and reverse primers included $5^{\prime}$-TTC CTC GAG ACT ATG GAA TGG GTT TGG GCG CTC GTG CT-3' and 5'-CCG CGG CCG CTC CTA CAA AAT GTT TCT TTC CGA TTT GC-3'. Full-length porcine RBP4 complementary DNA (cDNA, GenBank Accession No. 397124) was amplified and inserted into the XhoI/NotI sites of the PLVX-IRES-ZsGreen lentiviral vector. RBP4 polymerase chain reaction (PCR) products and pLVX-IRES-ZsGreen plasmid were excised by digesting with XhoI 
and NotI respectively. Porcine RBP4 gene was inserted into the pLVX-IRES-ZsGreen lentiviral vector to generate the pLVX-RBP4-IRES-ZsGreen construct. Approximately $24 \mathrm{~h}$ before transduction, 293T cells were seeded into $100 \mathrm{~mm}$ plates at $4 \times 10^{6}$ cells/plate and $10 \mathrm{~mL}$ growth medium and then incubated at $37^{\circ} \mathrm{C}, 5 \% \mathrm{CO}_{2}$ overnight. Then, the cells were further incubated until 80-90\% confluency. Four packaged systems of plasmids (Invitrogen, Carlsbad, CA, USA) included pLVX-IRES-ZsGreen vector, structure plasmid PLP1, PLP2, and envelope plasmid VSVG. FuGENE HD reagent (Roche, Mannheim, Germany), following the manufacturer's instructions, was used to transfect the 293T cells by mixing vector plasmid pLVX-RBP4-IRES-ZsGreen, structure plasmid PLP1, PLP2, and envelope plasmid VSVG at a mass ratio of 4:2:1:1. The cells with blank pLVX-IRES-ZsGreen (vector) transfection were used as negative controls. After 48 and $72 \mathrm{~h}$, viral particles from the culture supernatants were collected by ultracentrifugation at $4{ }^{\circ} \mathrm{C}, 72,000 \times g$ for $2.5 \mathrm{~h}$. A limiting dilution assay established that the titer of the virus detected by the green fluorescent protein (GFP)-labeled method was $1.2 \times 10^{7}$ transduction units (TU)/mL according to previously reported protocol [26]. GCs were divided into two groups: pLVX-RBP4-IRES-ZsGreen (pLVX-RBP4) and pLVX-IRES-ZsGreen (CTRL) groups. Each group was performed in biological triplicate. The lentiviral particles were added to the GCs at a multiplicity of infection of 50. The GCs were infected with lentiviral particles for $72 \mathrm{~h}$, and the medium with lentiviral particles was replaced every $24 \mathrm{~h}$. After $72 \mathrm{~h}$ of incubation, enhanced GFP (EGFP) was observed under a fluorescence microscope. RBP4 expression was quantified by real-time quantitative polymerase chain reaction (RT-qPCR) and Western blotting analysis.

\subsection{Total RNA Extraction and Real-Time Quantitative Polymerase Chain Reaction (RT-qPCR)}

Total RNA of GCs from three independent biological repetitions of the pLVX-RBP4 and CTRL groups with TRIZOL reagent (Qiagen, Hilden, Germany) was extracted according to manufacturer's protocol. RNA concentration and purification were assessed using a NanoDrop 2000 spectrophotometer (Thermo Fisher, Waltham, MA, USA); the number of OD260/OD280 must be higher than 1.8. RNA integrity was detected by agarose gel electrophoresis. Total RNA was reverse-transcribed into cDNA by using PrimeScript 1st strand cDNA Synthesis Kit (Takara). The total volume of $20 \mu \mathrm{L}$ RT-PCR reaction mixture contained $10 \mu \mathrm{L}$ SYBR ${ }^{\circledR}$ Green Real-time PCR Master Mix (Takara), $2 \mu \mathrm{L}$ cDNA, $7 \mu \mathrm{L}$ $\mathrm{ddH}_{2} \mathrm{O}$, and $0.5 \mu \mathrm{M}$ each of forward and reverse primers. The program used for all genes consisted of a denaturing cycle of $120 \mathrm{~s}$ at $95^{\circ} \mathrm{C}, 40$ cycles of PCR $\left(94^{\circ} \mathrm{C}\right.$ for $30 \mathrm{~s}, 59-61{ }^{\circ} \mathrm{C}$ for $30 \mathrm{~s}$, and $72{ }^{\circ} \mathrm{C}$ for $60 \mathrm{~s}$ ), a melting cycle consisting of $95^{\circ} \mathrm{C}$ for $30 \mathrm{~s}, 72{ }^{\circ} \mathrm{C}$ for $5 \mathrm{~min}$, and a step cycle starting at $65^{\circ} \mathrm{C}$ with a $0.2^{\circ} \mathrm{C} / \mathrm{s}$ transition rate to $95^{\circ} \mathrm{C}$. RT-qPCR analysis was conducted on an Mx3000P system (Stratagene, San Diego, CA, USA) with SYBR-Green detection according to manufacturer's instructions. The expression level of GAPDH was used as endogenous control. Relative expression was calculated using the $2^{-\Delta \Delta \mathrm{Ct}}$ method. The primer sequences are listed in Table S1.

\subsection{Western Blotting}

Extraction of proteins from GCs and subsequent quantification were performed as previously described [27]. Equal amounts $(40 \mu \mathrm{g})$ of proteins were resolved by $10 \%$ sodium dodecyl sulfate polyacrylamide gel electrophoresis and transferred onto polyvinylidene fluoride membranes. After blocking, the membranes were incubated overnight at $4{ }^{\circ} \mathrm{C}$ with anti-RBP4 mouse monoclonal antibody (1:300; Bioworld, Nanjing, China) and anti- $\beta$-actin rabbit monoclonal antibody (1:1000; Boster, Wuhan, China). After incubation with the primary antibodies, the membranes were washed thrice with TBST and then incubated for $1 \mathrm{~h}$ with 3000-fold diluted HRP-labeled goat anti-rabbit or goat anti-mouse secondary antibodies (Boster, Wuhan, China) at room temperature. After incubation, the membrane was washed thrice with TBST at 5 min intervals. After washing, each membrane was covered with enhanced chemiluminescence Western blotting reagents (Beyotime, Shanghai, China) for the detection of protein bands. 


\subsection{RNA-Sequencing Library Construction}

Six RNA-sequencing (RNA-seq) libraries (three RNA-seq libraries for pLVX-RBP4 group and three RNA-seq libraries for CTRL group) were generated using an NEBNext Ultra RNA Library Prep Kit for Illumina (NEB, Ipswich, MA, USA) according to the manufacturer's recommendations. A total amount of $1 \mu \mathrm{g}$ RNA per sample was submitted to HiSeqTM 2500 (Illumina Inc., San Diego, CA, USA) for cDNA library preparation. The library was sequenced by pair-end sequencing, and $125 \mathrm{bp}$ paired end reads were generated. Primary sequencing data produced using the Illumina HiSeqTM 2500 system were considered raw reads. Raw sequencing data generally featured clean reads, reads with a sequencing primer, tags containing $\mathrm{N}$, and adapter sequences. Raw reads were filtered into clean reads by FAST-QC [28].

\subsection{Identification of Differentially Expressed Genes (DEGs)}

TopHat2 software was used for aligning the clean reads to the current pig reference genome (Sscrofa10.2) [29]. The unigene numbers were converted into Entrez Gene ID numbers using the online g:profile conversion tool (http://biit.cs.ut.ee/gprofiler/). Gene expression levels were calculated by fragments per kilo bases per million mapped reads (FPKM). The screening of DEGs used Cuffdiff command of Cufflinks Software. The criteria filtering DEGs were as follows: (1) $p$-value $<0.05$ and $q$-value (adjusted $p$-value) $<0.05$; (2) |fold change $\mid \geq 2$ or $\leq 1$ in both groups. The criteria for screening the top 10 genes are based on fold change values.

\subsection{Functional Enrichment Analysis}

Go term enrichment analysis was conducted for upregulated and downregulated genes using the $\mathrm{R}$ package clusterProfiler [30]. In GO term tests, completely annotated genes of swine were appointed as the background. Kyoto Encyclopedia of Genes and Genomes (KEGG) (http://www.genome.jp/kegg) was used to identify the metabolic pathways or signal transduction pathways that were significantly enriched with DEGs by comparing them to the entire genome background (Figure 1). Fisher's exact test was applied to identify the significant GO categories and KEGG pathways. Only GO terms or KEGG pathways with $p$-values $<0.05$ were considered to be significantly enriched [31]. Protein-protein interaction (PPI) analysis of DEGs was based on the STRING database v11.0 [32]. All RNA-seq data were deposited into the Gene Expression Omnibus (GEO) database from NCBI (https://www.ncbi.nlm.nih.gov/geo). The accession record of GEO is GSE132962.

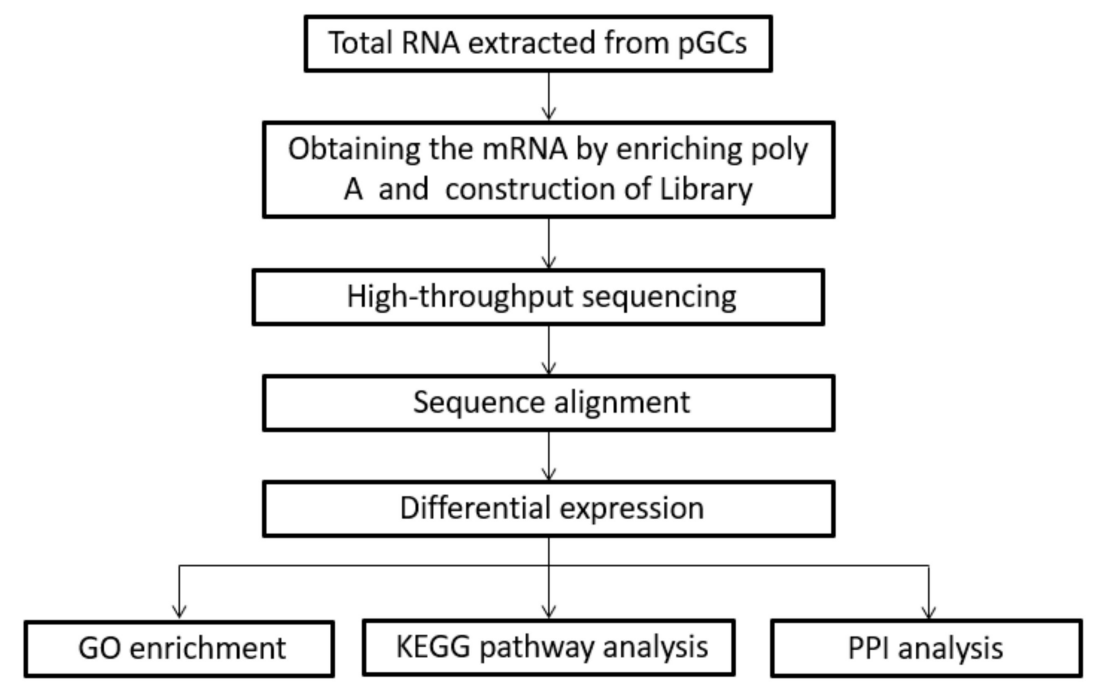

Figure 1. Workflow of high-throughput sequencing. GC: Granulosa cells, GO: gene ontology, KEGG: Kyoto Encyclopedia of Genes and Genomes, PPI: Protein-protein interaction 


\subsection{Statistical Analysis}

SPSS version 17.0 (SPSS, Inc., Chicago, IL, USA) was used for statistical analysis. The Student's $t$-test was performed to analyze statistical differences between means. All values were expressed as mean \pm SEM (standard error of the mean). $p<0.05$ was considered statistically significant.

\section{Results}

\subsection{Infection Efficiency}

The recombinant lentiviral was successfully infected into GCs. EGFP was detected by fluorescence microscopy in the transfected group (Figure 2a,b). RT-qPCR indicated a significant increase in RBP4 messenger RNA (mRNA) abundance in the pLVX-RBP4 group (Figure 2c). Western blotting results showed that the RBP4 protein was upregulated in the pLVX-RBP4 group (Figure 2d).

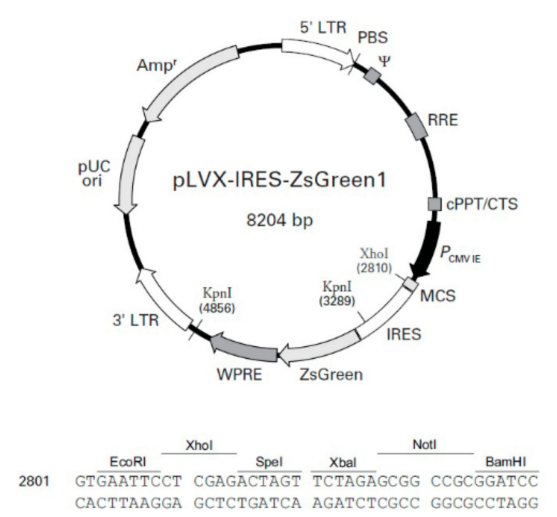

(a)

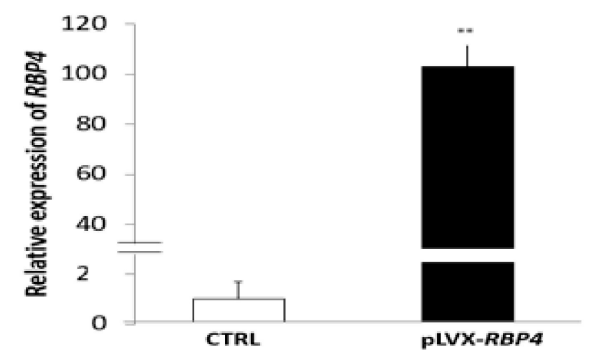

(c)

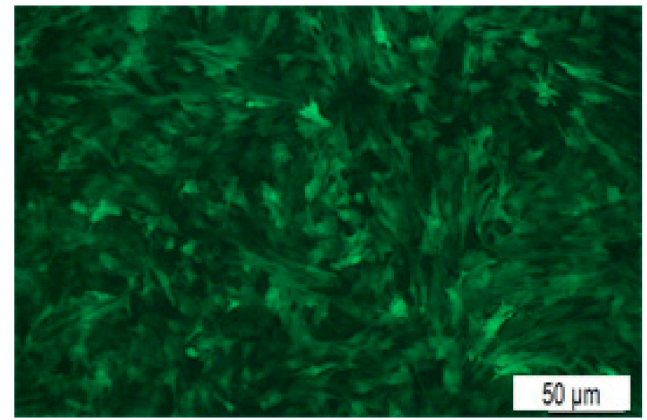

(b)

pLVX-RBP4 CTRL

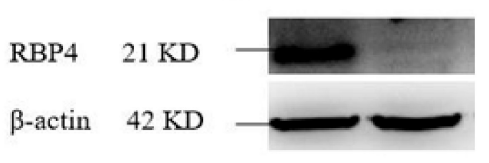

(d)

Figure 2. Overexpression of retinol binding protein 4 (RBP4) in GCs. (a) pLVX-IRES-ZsGreen vector. (b) GCs expressing green fluorescent protein (GFP) could be observed after infection by RBP4 lentivirus particles under fluorescence microscope (20×). (c) RBP4 mRNA expression levels in GCs after $72 \mathrm{~h}$ of lentivirus transfection. ( ${ }^{* *} p<0.01$ ). (d) RBP4 protein $(21 \mathrm{KD})$ expression upon RBP4 overexpression in GCs. $\beta$-Actin was used as an internal control (42 KD). CTRL: control.

\subsection{Transcriptome Profiling Analysis}

High-throughput sequencing was performed in biological triplicates to elucidate the regulatory mechanism of response of GCs to RBP4 overexpression. Six libraries of the pLVX-RBP4 and control (CTRL) groups of GCs were sequenced. Table S2 summarizes the results on the six libraries. In this study, 4.505-5.011 Gb of raw bases were obtained, and 33.747-40.089 $\mathrm{Mb}$ of raw reads were generated from the three libraries of the PLVX-RBP4 group. After quality control, 30.104-35.282 Mb of clean reads were obtained. Furthermore, Q20, Q30, and total mapped ratio were calculated (Table S2). 


\subsection{Differential Expression of Messenger RNAs in Granulosa Cells (GCs)}

High-throughput sequencing was conducted in biological triplicates to identify differential expression of mRNAs in GCs. From 17,053 expressed mRNAs, 16,471 and 16,259 genes were expressed in the pLVX-RBP4 and CTRL groups, respectively. Of these genes, 15,677 genes were expressed in both groups, whereas 794 and 582 genes were expressed only in the pLVX-RBP4 and CTRL groups, respectively (Figure 3a; Table S3). A total of 113 differentially expressed genes (DEGs), including 71 upregulated genes and 42 downregulated genes, were identified in pLVX-RBP4 group compared with the CTRL group (Figure 3b; Table S4). The 10 most upregulated genes included RBP4, HSPB1, MMP1, RBM34, S100A12, ITGA5, TOMM6, KIF20B, CCDC33, and MITD1. The 10 most downregulated genes comprised KCNMA1, IGFALS, LCN2, WIPF3, CD248, CRTC3, MAP1B, RAB3B, CPAMD8, and PRRC2C (Table 1).

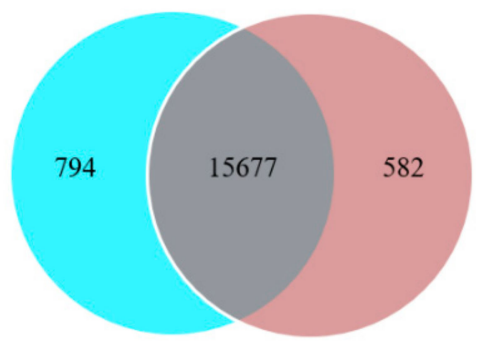

(a)

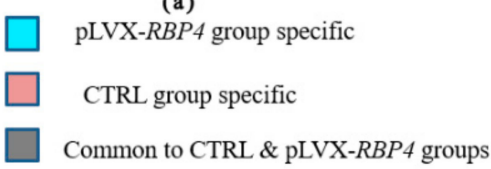

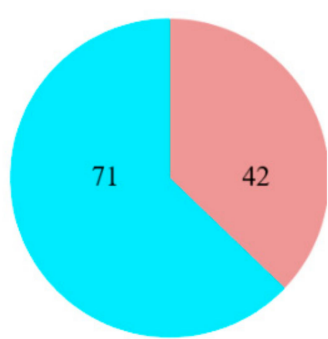

(b)

upregulated genes

downregulated genes

Figure 3. Sequencing analyses of genes expressed in GCs of pLVX-RBP4 and CTRL groups. (a) Venn diagram showing the overlapping genes expressed in different groups. (b) The numbers of upregulated and downregulated differentially expressed genes (DEGs) under overexpression of retinol binding protein $4(R B P 4)$.

Table 1. Top 10 upregulated and downregulated genes in granulosa cells (GCs) of pLVX-RBP4 group compared with the CTRL group.

\begin{tabular}{|c|c|c|}
\hline Gene Symbol & Gene Name & Description and Summary of the Function \\
\hline \multicolumn{3}{|l|}{ Upregulated } \\
\hline RBP4 & Plasma retinol binding protein 4 & $\begin{array}{l}\text { Plays a role in retinol transport; involved in insulin } \\
\text { resistance and diabetes }\end{array}$ \\
\hline HSPB1 & Heat shock protein 27 & $\begin{array}{l}\text { Provides thermotolerance in vivo and support cell } \\
\text { survival under stress conditions }\end{array}$ \\
\hline MMP1 & Matrix metallopeptidase 1 & Involved in the breakdown of extracellular matrix \\
\hline RBM34 & RNA binding motif protein 34 & $\begin{array}{l}\text { Ubiquitous expression in testis, lymph node, and } \\
\text { other tissues }\end{array}$ \\
\hline S100A12 & S100 calcium-binding protein A12 & $\begin{array}{l}\text { Involved in the regulation of cell cycle progression } \\
\text { and differentiation and specific calcium-dependent } \\
\text { signal transduction }\end{array}$ \\
\hline ITGA5 & Integrin $\alpha-5$ & Participates in cell-surface mediated signaling \\
\hline TOMM6 & Mitochondrial import receptor subunit TOM6 & May play a role in breast carcinogenesis \\
\hline KIF20B & kinesin-like protein 20A & $\begin{array}{l}\text { Could promote cancer progression and is essential } \\
\text { for cytokinesis in cell cycle }\end{array}$ \\
\hline CCDC33 & Coiled-coil domain-containing protein 33 & May be regulated by hormone and nutrition \\
\hline MITD1 & $\begin{array}{l}\text { Microtubule interacting and trafficking } \\
\text { domain containing } 1\end{array}$ & Participates in the abscission phase of cytokinesis \\
\hline
\end{tabular}


Table 1. Cont.

\begin{tabular}{|c|c|c|}
\hline Gene Symbol & Gene Name & Description and Summary of the Function \\
\hline \multicolumn{3}{|l|}{ Downregulated } \\
\hline KCNMA1 & $\begin{array}{l}\text { Potassium calcium-activated channel } \\
\text { subfamily } \mathrm{M} \propto 1\end{array}$ & $\begin{array}{l}\text { Relates with several cancers, such as breast } \\
\text { carcinoma, prostate cancer, and cervical cancers }\end{array}$ \\
\hline IGFALS & $\begin{array}{l}\text { Insulin like growth factor binding protein } \\
\text { acid labile subunit }\end{array}$ & Act as IGFBPs, binding IGFs exerts its function \\
\hline LCN2 & Lipocalin-2 & $\begin{array}{l}\text { Estradiol can regulate the expression of } L C N 2 \text { and is } \\
\text { linked to IR }\end{array}$ \\
\hline WIPF3 & Wasl interacting protein family member 3 & $\begin{array}{l}\text { May be a regulator of cytoskeletal organization and } \\
\text { play a role in spermatogenesis }\end{array}$ \\
\hline CD248 & Endosialin & Essential for embryo development \\
\hline CRTC3 & Creb-regulated transcription coactivator 3 & $\begin{array}{l}\text { Transcriptional coactivator; plays roles in adipose } \\
\text { development and energy metabolism }\end{array}$ \\
\hline$M A P 1 B$ & Microtubule-associated protein 1B & $\begin{array}{l}\text { Plays an important role in development and function } \\
\text { of the nervous system }\end{array}$ \\
\hline$R A B 3 B$ & Ras-related protein-3B & $\begin{array}{l}\text { May play a role in regulating GLUT4 translocation in } \\
\text { adipocytes }\end{array}$ \\
\hline CPAMD8 & $\begin{array}{l}\mathrm{C} 3 \text { and pzp-like } \alpha \text {-2-macroglobulin } \\
\text { domain-containing protein } 8\end{array}$ & May be associated with cataract development \\
\hline PRRC2C & Proline rich coiled-coil 2C & Involved in the development of basement membrane \\
\hline
\end{tabular}

\subsection{Validation of Differentially Expressed Messenger RNAs}

In accordance with previous reports, the top 10 up- and downregulated DEGs were selected for further validation by RT-qPCR analysis to validate the DEGs that were identified by RNA sequencing. We observed the upregulation of nine genes (RBP4, HSPB1, MMP1, RBM34, S100A12, ITGA5, TOMM6, KIF20B, and MITD1) by high-throughput sequencing, and this finding was confirmed by RT-qPCR. RT-qPCR also confirmed the downregulation of nine genes revealed by high-throughput sequencing. RNA sequencing showed that CCDC33 and CD248 were differentially expressed compared with the CTRL group, but RT-qPCR failed to confirm the data. The results demonstrated that differential expression was validated for 18 of 20 genes (Figure 4).

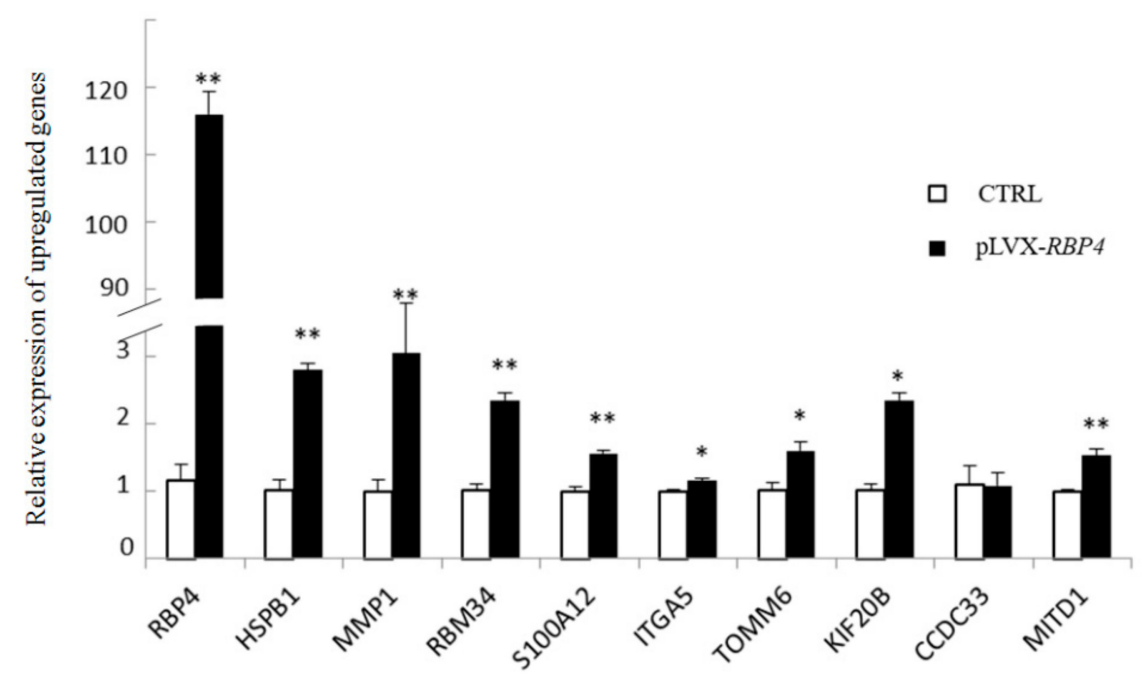

(a)

Figure 4. Cont. 


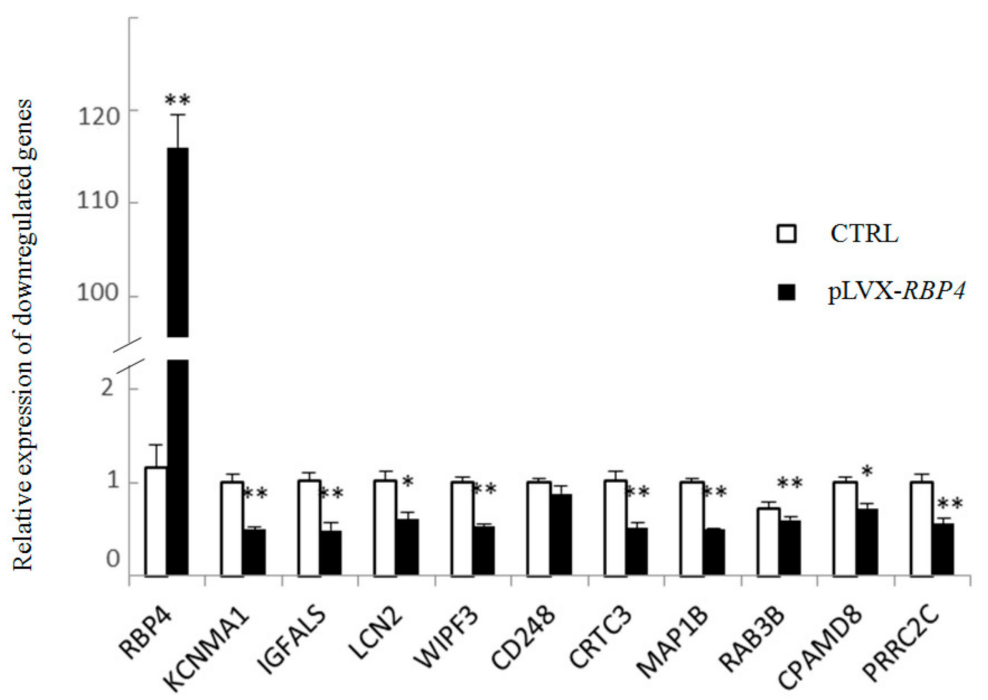

(b)

Figure 4. Relative expression of selected mRNAs was quantified by real-time quantitative polymerase chain reaction (RT-qPCR) $\left({ }^{*} p<0.05 ;{ }^{* *} p<0.01\right)$. (a) Relative expression of 10 upregulated genes. (b) Relative expression of 10 downregulated genes.

\subsection{Gene Ontology Annotation and Kyoto Encyclopedia of Genes and Genomes Enrichment Analysis of} Differentially Expressed Genes

Gene ontology includes biological processes (BP), cellular components (CC), and molecular functions (MF). GO terms with $p<0.05$ were considered significantly enriched. Table 2 lists the top 30 significant GO terms, including BP, MF, and CC. Accordingly, the MF functions mainly related to protein binding, protein homodimerization activity, and growth factor binding were significantly enriched, including ribosomal subunit and mitochondrial part as GO terms for CC. In the BP category, the DEGs enriched in GO terms included protein folding, regulation of interleukin-1 production, mitotic cell cycle, and regulation of intrinsic apoptotic signaling pathway (Table 2).

Table 2. Top 30 significant terms from Enrich Gene Ontology for biological processes (BP), molecular functions (MF), and cellular components (CC).

\begin{tabular}{|c|c|c|c|}
\hline GO Terms & Gene Name & Gene Ratio & $p$-Value \\
\hline \multicolumn{4}{|l|}{ Biological process (BP) } \\
\hline GO:0006457-protein folding & HSPB1, PFDN4, PFDN2, PRDX4 & $6.3 \%$ & 0.000427 \\
\hline GO:0006887-exocytosis & $K I T, R A B 3 B$ & $2.7 \%$ & 0.00471 \\
\hline GO:0032652-regulation of interleukin-1 production & HSPB1, ANXA1 & $10.5 \%$ & 0.00508 \\
\hline GO:0016477-cell migration & KIT, PEAK1, CD248 & $1.1 \%$ & 0.00512 \\
\hline GO:0032612-interleukin-1 production & HSPB1, ANXA1 & $10.0 \%$ & 0.00562 \\
\hline GO:0048870-cell motility & KIT, PEAK1, CD248 & $1.0 \%$ & 0.00688 \\
\hline GO:0051674-localization of cell & KIT, PEAK1, CD248 & $1.0 \%$ & 0.00688 \\
\hline GO:0040011-locomotion & KIT, PEAK1, CD248 & $0.9 \%$ & 0.0107 \\
\hline \multicolumn{4}{|l|}{ GO:0006928-movement of cell or } \\
\hline subcellular component & KIT, PEAK1, CD248 & $0.9 \%$ & 0.0117 \\
\hline GO:0000278-mitotic cell cycle & MITD1, CDK1, NUF2, RPL26 & $6.3 \%$ & 0.0127 \\
\hline \multicolumn{4}{|l|}{ Molecular function (MF) } \\
\hline GO:0005520-insulin-like growth factor binding & IGFBP5, IGFALS & $12.5 \%$ & 0.000330 \\
\hline $\begin{array}{c}\text { GO:0044183-protein binding involved in } \\
\text { protein folding }\end{array}$ & HSPB1, PFDN2 & $20.0 \%$ & 0.00137 \\
\hline GO:0042803-protein homodimerization activity & HSPB1, MITD1, CACYBP, AIMP1, PRDX4 & $3.3 \%$ & 0.00148 \\
\hline GO:0003735-structural constituent of ribosome & MRPL52, RPL26, RPL26L1, RPL23 & $4.4 \%$ & 0.00155 \\
\hline GO:0019838-growth factor binding & IGFBP5, IGFALS & $5.7 \%$ & 0.00161 \\
\hline GO:0004713-protein tyrosine kinase activity & KIT, PEAK1 & $4.3 \%$ & 0.00277 \\
\hline $\begin{array}{l}\text { GO:0016684-oxidoreductase activity, acting on } \\
\text { peroxide as acceptor }\end{array}$ & GPX8, PRDX4 & $9.1 \%$ & 0.00675 \\
\hline
\end{tabular}


Table 2. Cont.

\begin{tabular}{|c|c|c|c|}
\hline GO Terms & Gene Name & Gene Ratio & $p$-Value \\
\hline GO:0016209-antioxidant activity & GPX8, PRDX4 & $5.7 \%$ & 0.0166 \\
\hline GO: 0051082-unfolded protein binding & PFDN4, PFDN2 & $5.7 \%$ & 0.0166 \\
\hline $\begin{array}{c}\text { GO:0046983-protein dimerization activity } \\
\text { Cellular component (CC) }\end{array}$ & HSPB1, MITD1, CACYBP, AIMP1, PRDX4 & $1.9 \%$ & 0.0169 \\
\hline GO:0015934-large ribosomal subunit & MRPL52, RPL26, RPL26L1, RPL23 & $7.8 \%$ & 0.000231 \\
\hline GO:0044391-ribosomal subunit & MRPL52, RPL26, RPL26L1, RPL23 & $4.9 \%$ & 0.00135 \\
\hline GO:0005739-mitochondrion & $\begin{array}{c}\text { MRPL50, NDUFB3, COX17, MTFP1, } \\
\text { MRPL52, COX6C, ATP5I, PFDN2, PRDX4 }\end{array}$ & $1.9 \%$ & 0.00141 \\
\hline GO:0005840-ribosome & MRPL52, RPL26, RPL26L1, RPL23 & $3.9 \%$ & 0.00327 \\
\hline GO:0044429-mitochondrial part & $\begin{array}{c}\text { NDUFB3, } C O X 17, \text { MTFP1, MRPL52, } \\
\text { COX6C, ATP5I }\end{array}$ & $2.2 \%$ & 0.00490 \\
\hline GO:0031967-organelle envelope & $\begin{array}{c}\text { NDUFB3, } C A C Y B P, C O X 17, M T F P 1, \\
\text { COX6C, ATP5I }\end{array}$ & $2.2 \%$ & 0.00567 \\
\hline GO:0031975-envelope & $\begin{array}{c}\text { NDUFB3, } C A C Y B P, C O X 17, M T F P 1 \\
\text { COX6C, ATP5I }\end{array}$ & $2.2 \%$ & 0.00567 \\
\hline GO: 0005740-mitochondrial envelope & NDUFB3, COX17, MTFP1, COX6C, ATP5I & $2.5 \%$ & 0.00660 \\
\hline GO: 0031970-organelle envelope lumen & CACYBP, COX17 & $9.5 \%$ & 0.00700 \\
\hline GO:0005743-mitochondrial inner membrane & NDUFB3, MTFP1, COX6C, ATP5I & $3.1 \%$ & 0.00749 \\
\hline
\end{tabular}

To better illustrate their biological functions, we divided the DEGs into two groups: upregulated and downregulated. In the BP analysis, the enriched GO terms for upregulated DEGs converged on protein folding, regulation of interleukin-1 production, and interleukin-1 production. On the other hand, the downregulated DEGs were focused on exocytosis and cell migration (Figures S1 and S2). In the MF category, the upregulated DEGs were mainly enriched in protein binding and downregulated DEGs were enriched in insulin-like growth factor binding and growth factor binding (Figures S3 and S4). In the CC category, the upregulated DEGs were mainly enriched in protein binding involved in large ribosomal subunit, ribosomal subunit, and mitochondrion (Figure S5).

All the DEGs were mapped to the KEGG database to further investigate their functions. A total of 28 DEGs were categorized into 16 pathways (Figure 5). The DEGs were determined to be involved in key pathways, such as oxidative phosphorylation, Parkinson's disease, non-alcoholic fatty liver disease (NAFLD), Huntington's disease, cardiac muscle contraction, Alzheimer's disease, fatty acid biosynthesis, AMPK signaling pathway, insulin signaling pathway, and tight junction. Most of these pathways are related to metabolic diseases.

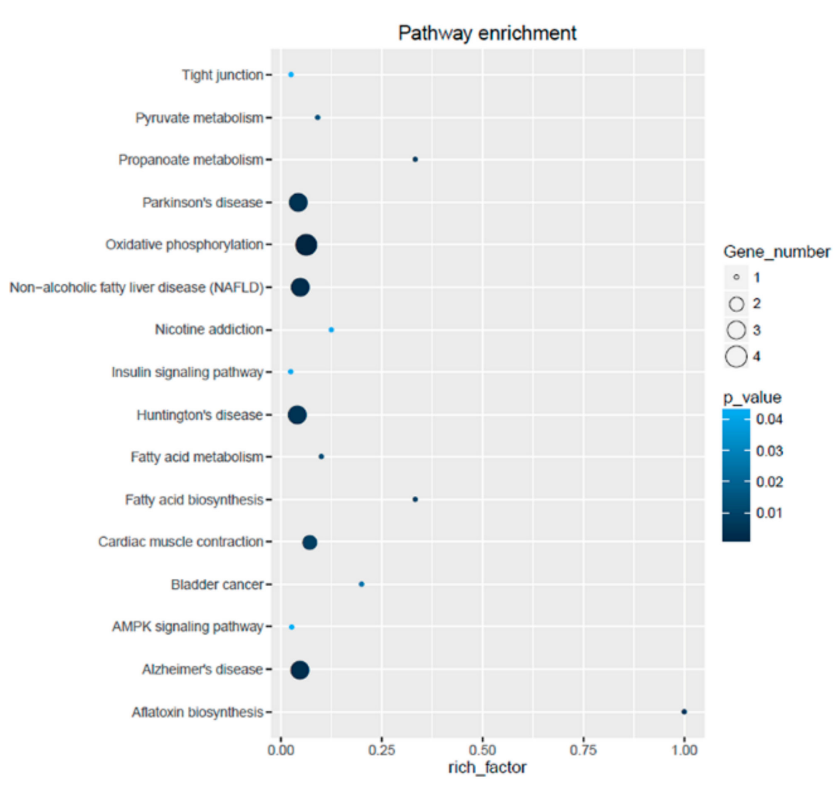

Figure 5. Detailed image of KEGG pathway enrichment. 


\subsection{Protein-Protein Interaction (PPI) Network Analysis}

An integral PPI network (Figure 6a) and three sub-networks (Figure 6b-d) were constructed by mapping the upregulated and downregulated DEGs. The integral network consisted of 65 proteins. Figure 6b contained seven proteins (COX17, cytochrome oxidase subunit 6A1 (COX6A1), COX6C, ATP5I, ubiquinone oxidoreductase subunit B3 (NDUFB3), TOMM6, and ENSSSCG00000013436), which were mainly related to oxidative phosphorylation, NAFLD, and Alzheimer's disease. Figure $6 c-d$ were related to cell cycle and cell ribosome, respectively. Figure 6d consisted of RPL26, RPL26L1, and RPL23, which are cytoplasmic ribosomal proteins.

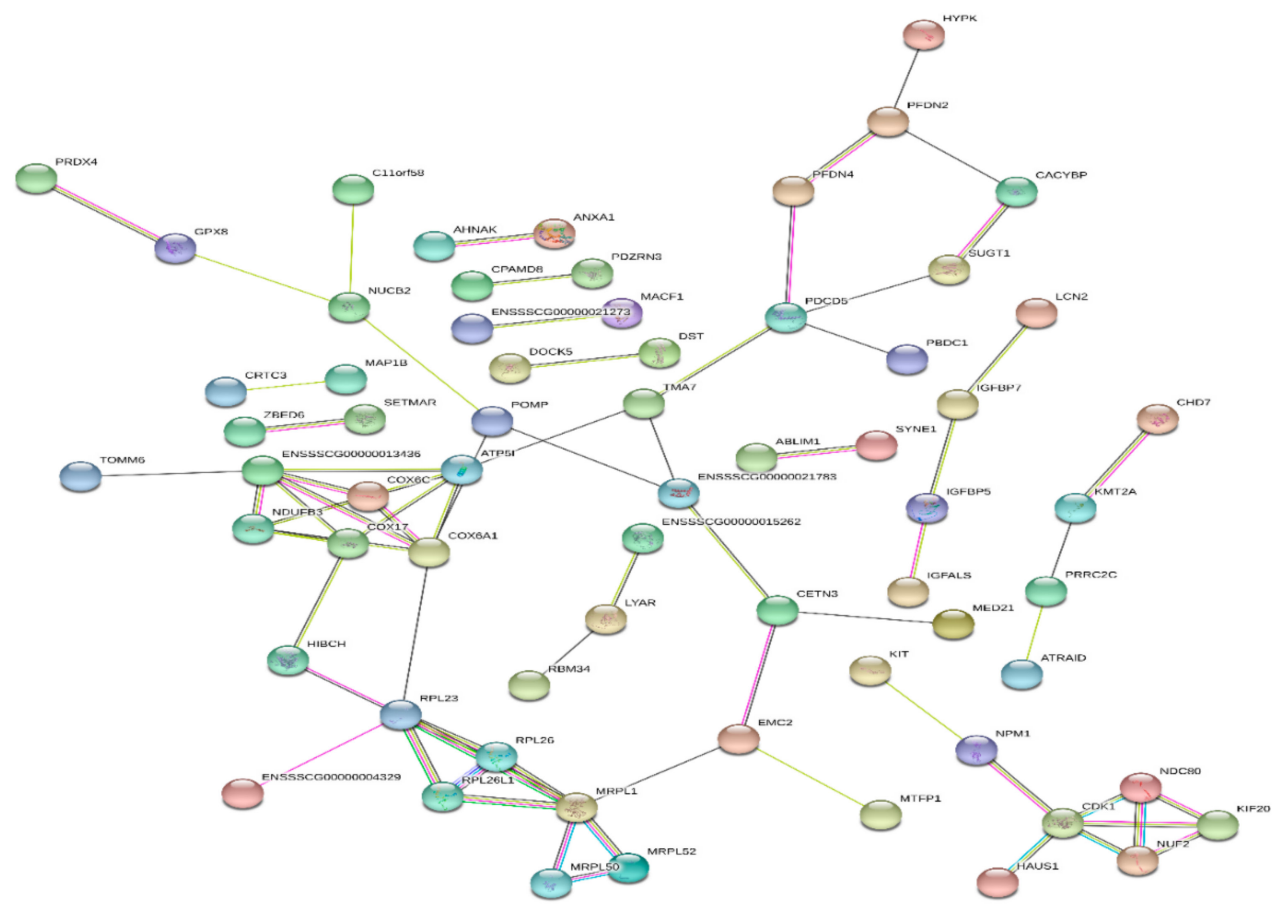

(a)

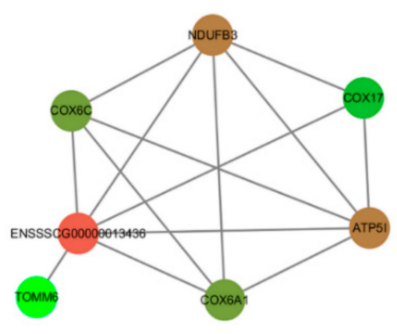

(b)

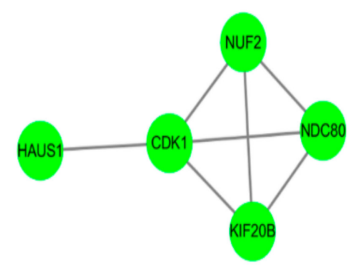

(c)

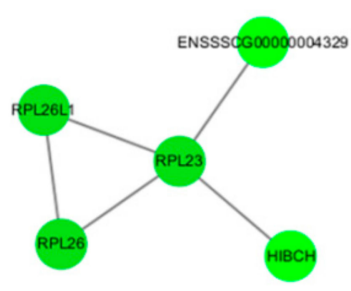

(d)

$$
\begin{aligned}
& \text { Known Interactions } \\
& \text { - }-\odot \text { from curated databases } \\
& \ominus-\ominus \text { experimentally determined }
\end{aligned}
$$
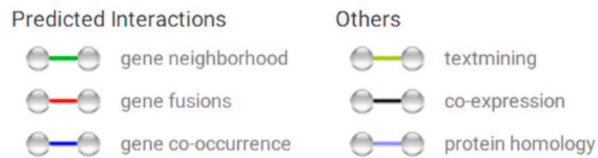

Figure 6. Protein-protein interaction (PPI) of the DEGs. (a) An integral PPI network, (b) Oxidative phosphorylation network, (c) Cell cycle network, (d) Cell ribosome network. The nodes represent proteins. The node color represents the connectivity between genes. Deeper color indicates a better connectivity between adjacent genes. 


\section{Discussion}

Granulosa cells are important somatic cells that surround oocytes. These cells are involved in ovarian follicular development in pigs. RBP4 is an approximately $21 \mathrm{KD}$ peptide that acts as a carrier of vitamin A in the plasma. This protein is one of the identified adipokines that are associated with IR, obesity, and type 2 diabetes [9]. RBP4 is highly related to ovarian diseases, such as PCOS, ovarian cancer in humans [12,33-36], and ovarian cysts in swine [22], which may be caused by endocrine disorders. Furthermore, previous studies have shown that RBP4 could promote cell proliferation. A study by Li indicated that RBP4 could increase the proliferation and invasion of HTR8 cells through suppressing PI3K/AKT signaling [37]. Another study demonstrated that RBP4 affected proliferation, differentiation, and mineralization of MC3T3-E1 cell line in vitro [38].

In the present study, we identified the effects of $R B P 4$ on GCs by transcriptomic analysis following $R B P 4$ overexpression. RNA-based overexpression of RBP4 changed the expression levels of 113 DEGs. In addition, our data revealed the effects of RBP4 of DEGs that are important to pathways in GCs, including oxidative phosphorylation, NAFLD, Alzheimer's disease, fatty acid biosynthesis, AMPK signaling pathway, and insulin signaling pathway.

Oxidative phosphorylation is involved in GC apoptosis and follicular atresia [39]. Abnormal mitochondrial oxidative phosphorylation occurs in obese girls with type 2 diabetes and IR, which are related to RBP4 [40]. The insulin signaling pathway participates in follicular development, GC proliferation, and developmental ability of oocytes in vitro [41,42]. Nevertheless, insulin pathway is also associated with ovarian diseases, such as PCOS, abnormal steroidogenesis, and ovarian cancer $[43,44]$. In mammals, the AMPK signaling pathway is involved in the regulation of many cellular functions, and studies indicated that AMPK signaling play roles in bovine GCs to express a proliferative and steroidogenic phenotype [45]. Another study recently proposed a relationship between the GZYKF (a Chinese medicine formula) effect and AMPK pathway that may underlie the modulation of GC autophagy [46].

The significant role of RBP4 is the transport of retinol from the liver to peripheral tissues. A recent study found that RBP4 was located in the granulosa and inner theca cell layers and the expression level of RBP4 in ovarian follicles increased with follicular sizes. GCs treated with increasing FSH or LH promoted the expression of RBP4 [24]. However, the minor number of DEGs was detected in this article. Further study is needed to clarify if RBP4 exerts its biological function through the synergy of other factors, such as transhyretin, FSH, LH, and cell membrane receptor STRA6. KEGG results are not directly related to reproductive pathways, nevertheless, oxidative phosphorylation, fatty acid biosynthesis, and AMPK signaling can affect the physiological function of GCs. Available data focusing on the relationship of RBP4 and type 2 diabetes mellitus, PCOS, and ovarian cancer have been originated from population-based prospective studies. However, in present study, some attractive DEGs related to reproduction and cell cycle were detected, such as MMP1, IGF signaling related genes (IGFBP5, IGFBP7, and IGFALS), HSPB1, and cell-cycle gene (CDK1).

Li et al. observed that $R B P 4$ knockdown decreased cell invasion, whereas RBP4 overexpression increased the invasion of HTR8/SVneo cells. Moreover, the production of MMPs increased with the increase in RBP4 expression [37]. The RBP4-stimulated expression of MMP1 in the present study supports the above notion. Furthermore, our results confirmed for the first time that IGFBP5, IGFBP7, and IGFALS were detected as DEGs in GCs overexpressing RBP4. Among these DEGs, IGFBP5 and IGFALS were downregulated, and IGFBP7 was upregulated. Interestingly, IGFBP5 and IGFALS were downregulated simultaneously, as IGF1, IGFBP5, and IGFALS function in a form of ternary complex for IGF signaling, which has been shown to play important roles in a variety of physiological processes, including protein chaperoning, steroidogenesis, and protection against apoptosis [47-50]. Upregulation of the expression of HSPB1 by RBP4 may have significant consequences for the production of HSPB1 in GCs. HSPB1 is a protein that appears to antagonize a molecular pathway for stress [51], and HSPB1 was demonstrated to be associated with folliculogenesis and steroidogenesis in bovine ovary [52]. Cyclin-dependent kinase 1 (CDK1) is a key regulator of the cell cycle and RNA transcription [53]. 
The hubs of CDK1 are upregulated in bovine GCs in luteal phase and small healthy follicles [54]. Meanwhile, in this research, the expression of CDK1, which also acts as a hub of PPI, was upregulated in GCs challenged with RBP4. In addition, previous studies have shown that RBP4 could promote cell proliferation. These results suggest that overexpression of $R B P 4$ promoted cell cycle in porcine GCs. Our data indicates that RBP4 plays a potential role in in ovarian folliculogenesis and pathogenesis.

\section{Conclusions}

In this study, we compared the differential expression of genes of porcine GCs overexpressing RBP4 by using high-throughput sequencing. In addition, our transcriptomic data support that several genes are involved in important biological processes associated with folliculogenesis and pathogenesis. As such, these findings provide novel insights on the role of RBP4 in porcine GCs.

Supplementary Materials: The following are available online at http://www.mdpi.com/2073-4425/10/8/615/s1. Table S1: Primers of RT-qPCR used in the present study; Table S2: Sequencing quality statistics for the GCs of pLVX-RBP4 and CTRL groups; Table S3: Genes expressed in pLVX-RBP4 group and CTRL group. Table S4: DEGs of pLVX-RBP4 group compared to CTRL group in the GCs. Figure S1: BP analysis of downregulated DEGs; Figure S2: BP analysis of upregulated DEGs; Figure S3: MF analysis of downregulated DEGs; Figure S4: MF analysis of upregulated DEGs; Figure S5: CC function analysis of upregulated DEGs.

Author Contributions: Conceptualization, Y.Z.; formal analysis, C.L.; writing-original draft preparation, X.Z. and Y.Z.; writing-review and editing, C.L. and X.Z.; supervision, X.Z.; project administration, Y.Z.

Funding: This research was funded by The National Natural Science Foundation of China, with grant Nos. 31372308, 31672417, and 31301969. The Science and Technology Development Project of Changchun, grant No. 17DY022.

Conflicts of Interest: The authors declare no conflict of interest. The funders had no role in the design of the study; in the collection, analyses, or interpretation of data; in the writing of the manuscript, or in the decision to publish the results.

\section{References}

1. Lawrence, J.; Payton, R.; Godkin, J.; Saxton, A.; Schrick, F.; Edwards, J. Retinol improves development of bovine oocytes compromised by heat stress during maturation. J. Dairy Sci. 2004, 87, 2449-2454. [CrossRef]

2. Suwa, H.; Kishi, H.; Imai, F.; Nakao, K.; Hirakawa, T.; Minegishi, T. Retinoic acid enhances progesterone production via the cAMP/PKA signaling pathway in immature rat granulosa cells. Biochem. Biophys. Rep. 2016, 8, 62-67. [CrossRef] [PubMed]

3. Elomda, A.M.; Saad, M.F.; Saeed, A.M.; Elsayed, A.; Abass, A.O.; Safaa, H.M.; Mehaisen, G.M.K. Antioxidant and developmental capacity of retinol on the in vitro culture of rabbit embryos. Zygote 2018, 26, 326-332. [CrossRef] [PubMed]

4. Fujihara, M.; Yamamizu, K.; Comizzoli, P.; Wildt, D.E.; Songsasen, N. Retinoic acid promotes in vitro follicle activation in the cat ovary by regulating expression of matrix metalloproteinase 9. PLoS ONE 2018, 13, e0202759. [CrossRef] [PubMed]

5. Kanai, M.; Raz, A.; Goodman, D.S. Retinol-binding protein: The transport protein for vitamin A in human plasma. J. Clin. Investig. 1968, 47, 2025-2044. [CrossRef] [PubMed]

6. Tsutsumi, C.; Okuno, M.; Tannous, L.; Piantedosi, R.; Allan, M.; Goodman, D.S.; Blaner, W.S. Retinoids and retinoid-binding protein expression in rat adipocytes. J. Biol. Chem. 1992, 267, 1805-1810. [PubMed]

7. Isken, A.; Golczak, M.; Oberhauser, V.; Hunzelmann, S.; Driever, W.; Imanishi, Y.; Palczewski, K.; Von Lintig, J. RBP4 disrupts vitamin A uptake homeostasis in a STRA6-deficient animal model for Matthew-Wood Syndrome. Cell Metab. 2008, 7, 258-268. [CrossRef]

8. Kawaguchi, R.; Yu, J.; Honda, J.; Hu, J.; Whitelegge, J.; Ping, P.; Wiita, P.; Bok, D.; Sun, H. A membrane receptor for retinol binding protein mediates cellular uptake of vitamin, A. Science 2007, 315, 820-825. [CrossRef]

9. Yang, Q.; Graham, T.E.; Mody, N.; Preitner, F.; Peroni, O.D.; Zabolotny, J.M.; Kotani, K.; Quadro, L.; Kahn, B.B. Serum retinol binding protein 4 contributes to insulin resistance in obesity and type 2 diabetes. Nature 2005, 436, 356-362. [CrossRef]

10. Li, F.; Xia, K.; Li, C.; Yang, T. Retinol-binding protein 4 as a novel risk factor for cardiovascular disease in patients with coronary artery disease and hyperinsulinemia. Am. J. Med. Sci. 2014, 348, 474-479. [CrossRef] 
11. Tan, B.K.; Chen, J.; Lehnert, H.; Kennedy, R.; Randeva, H.S. Raised serum, adipocyte, and adipose tissue retinol-binding protein 4 in overweight women with polycystic ovary syndrome: Effects of gonadal and adrenal steroids. J. Clin. Endocrinol. Metab. 2007, 92, 2764-2772. [CrossRef] [PubMed]

12. Wang, Y.; Wang, Y.; Zhang, Z. Adipokine RBP4 drives ovarian cancer cell migration. J. Ovarian Res. 2018, 11, 29. [CrossRef] [PubMed]

13. Marantidis, A.; Laliotis, G.P.; Avdi, M. Association of RBP4 genotype with phenotypic reproductive traits of sows. Genet. Res. Int. 2016, 2016, 4940532. [CrossRef] [PubMed]

14. Brown, J.A.; Eberhardt, D.M.; Schrick, F.N.; Roberts, M.P.; Godkin, J.D. Expression of retinol-binding protein and cellular retinol-binding protein in the bovine ovary. Mol. Reprod. Dev. 2003, 64, 261-269. [CrossRef] [PubMed]

15. Levi, L.; Levavi-Sivan, B.; Lubzens, E. Expression of genes associated with retinoid metabolism in the trout ovarian follicle1. Biol. Reprod. 2008, 79, 570-577. [CrossRef] [PubMed]

16. Liu, R.Z.; Denovan-Wright, E.M.; Degrave, A.; Thisse, C.; Thisse, B.; Wright, J.M. Spatio-temporal distribution of cellular retinol-binding protein gene transcripts (CRBPI and CRBPII) in the developing and adult zebrafish (Danio rerio). JBIC J. Biol. Inorg. Chem. 2004, 271, 339-348. [CrossRef]

17. Pomp, D.; Geisert, R.D.; Yelich, J.V. Detection of transcripts for retinoic acid receptors, retinol-binding protein, and transforming growth factors during rapid trophoblastic elongation in the porcine conceptus. Biol. Reprod. $1997,57,286-294$.

18. Harney, J.P.; Ott, T.L.; Geisert, R.D.; Bazer, F.W. Retinol-binding protein gene expression in cyclic and pregnant endometrium of pigs, sheep, and cattle. Biol. Reprod. 1993, 49, 1066-1073. [CrossRef]

19. Trout, W.E.; McDonnell, J.J.; Kramer, K.K.; Baumbach, G.A.; Roberts, R.M. The retinol-binding protein of the expanding pig blastocyst: Molecular cloning and expression in trophectoderm and embryonic disc. Mol. Endocrinol. 1991, 5, 1533-1540. [CrossRef]

20. Roberts, R.M.; Xie, S.; Trout, W.E. Embryo-uterine interactions in pigs during week 2 of pregnancy. J. Reprod. Fertil. Suppl. 1993, 48, 171-186.

21. Albertini, D.; Combelles, C.; Benecchi, E.; Carabatsos, M. Cellular basis for paracrine regulation of ovarian follicle development. Reproduction 2001, 121, 647-653. [CrossRef]

22. Sun, Y.L.; Ping, Z.G.; Li, C.J.; Sun, Y.F.; Yi, K.L.; Li, X.Y.; Wang, X.L.; Zhou, X. Comparative proteomic analysis of follicular fluids from normal and cystic follicles in sows. Reprod. Domest. Anim. 2011, 46, 889-895. [CrossRef] [PubMed]

23. Jiang, Y.; Zhao, Y.; Chen, S.; Chen, L.; Li, C.; Zhou, X. Regulation by FSH of the dynamic expression of retinol-binding protein 4 in the mouse ovary. Reprod. Biol. Endocrinol. 2018, 16, 25. [CrossRef] [PubMed]

24. Rao, J.; Chen, J.; Bi, M.; Zhang, Y.; Chen, S.; Zhao, Y.; Wang, F.; Qiu, T.; Chen, L.; Li, C.; et al. Interaction between the expression of retinol binding protein 4 and gonadotropin receptors in follicular granulosa cells of pigs. Livest. Sci. 2019, 220, 205-210. [CrossRef]

25. Li, Y.; Ganta, S.; Von Stein, F.B.; Mason, D.E.; Mitchell, B.M.; Freeman, L.C. 4-aminopyridine decreases progesterone production by porcine granulosa cells. Reprod. Biol. Endocrinol. 2003, 1, 31. [CrossRef] [PubMed]

26. Eggers, R.; Hendriks, W.T.; Tannemaat, M.R.; Van Heerikhuize, J.J.; Pool, C.W.; Carlstedt, T.P.; Zaldumbide, A.; Hoeben, R.C.; Boer, G.J.; Verhaagen, J. Neuroregenerative effects of lentiviral vector-mediated GDNF expression in reimplanted ventral roots. Mol. Cell. Neurosci. 2008, 39, 105-117. [CrossRef] [PubMed]

27. Ongeri, E.M.; Verderame, M.F.; Hammond, J.M. Follicle-stimulating hormone induction of ovarian insulin-like growth factor-binding protein-3 transcription requires a TATA box-binding protein and the protein kinase A and phosphatidylinositol-3 kinase pathways. Mol. Endocrinol. 2005, 19, 1837-1848. [CrossRef]

28. Chen, S.F.; Zhou, Y.Q.; Chen, Y.R.; Gu, J. fastp: an ultra-fast all-in-one FASTQ preprocessor. Bioinformatics 2018, 34, 884-890. [CrossRef]

29. Kim, D.; Pertea, G.; Trapnell, C.; Pimentel, H.; Kelley, R.; Salzberg, S.L. TopHat2: Accurate alignment of transcriptomes in the presence of insertions, deletions and gene fusions. Genome Biol. 2013, 14. [CrossRef]

30. Yu, G.; Wang, L.G.; Han, Y.; He, Q.Y. clusterprofiler: An R package for comparing biological themes among gene clusters. OMICS: A J. Integr. Biol. 2012, 16, 284-287. [CrossRef]

31. Anders, S.; Reyes, A.; Huber, W. Detecting differential usage of exons from RNA-seq data. Nat. Précéd. 2012, 22, 2008-2017. 
32. Szklarczyk, D.; Gable, A.L.; Lyon, D.; Junge, A.; Wyder, S.; Huerta-Cepas, J.; Simonovic, M.; Doncheva, N.T.; Morris, J.H.; Bork, P.; et al. STRING v11: Protein-protein association networks with increased coverage, supporting functional discovery in genome-wide experimental datasets. Nucleic Acids Res. 2019, 47, D607-D613. [CrossRef] [PubMed]

33. Lorkova, L.; Pospisilova, J.; Lacheta, J.; Leahomschi, S.; Zivny, J.; Cibula, D.; Zivny, J.; Petrak, J. Decreased concentrations of retinol-binding protein 4 in sera of epithelial ovarian cancer patients: A potential biomarker identified by proteomics. Oncol. Rep. 2012, 27, 318-324. [PubMed]

34. Jeon, Y.E.; Lee, K.E.; Jung, J.A.; Yim, S.Y.; Kim, H.; Seo, S.K.; Cho, S.; Choi, Y.S.; Lee, B.S. Kisspeptin, leptin, and retinol-binding protein 4 in women with polycystic ovary syndrome. Gynecol. Obstet. Investig. 2013, 75, 268-274. [CrossRef] [PubMed]

35. Cheng, Y.S.; Liu, C.D.; Zhang, N.W.; Wang, S.D.; Zhang, Z.Y. Proteomics analysis for finding serum markers of ovarian cancer. Biomed. Res. Int. 2014, 2014, 179040. [CrossRef] [PubMed]

36. Salilew-Wondim, D.; Wang, Q.; Tesfaye, D.; Schellander, K.; Hoelker, M.; Hossain, M.M.; Tsang, B.K. Polycystic ovarian syndrome is accompanied by repression of gene signatures associated with biosynthesis and metabolism of steroids, cholesterol and lipids. J. Ovarian Res. 2015, 8, 24. [CrossRef] [PubMed]

37. Li, H.; Cao, G.; Zhang, N.; Lou, T.; Wang, Q.; Zhang, Z.; Liu, C. RBP4 regulates trophoblastic cell proliferation and invasion via the PI3K/AKT signaling pathway. Mol. Med. Rep. 2018, 18, 2873-2879. [CrossRef] [PubMed]

38. Ghanem, A.; Lu, Y.H.; Cai, T.Y.; Mu, X.Z. Overexpression of RBP4 promotes proliferation, differentiation and mineralization of MC3T3-E1. Int. J. Clin. Exp. Pathol. 2017, 10, 298-305.

39. Asselin, É.; Xiao, C.W.; Wang, Y.F.; Tsang, B.K. Mammalian follicular development and atresia: Role of apoptosis. Neurosignals 2000, 9, 87-95. [CrossRef]

40. Cree-Green, M.; Newcomer, B.R.; Coe, G.; Newnes, L.; Baumgartner, A.; Brown, M.S.; Pyle, L.; Reusch, J.E.; Nadeau, K.J. Peripheral insulin resistance in obese girls with hyperandrogenism is related to oxidative phosphorylation and elevated serum free fatty acids. Am. J. Physiol. Metab. 2015, 308, E726-E733. [CrossRef]

41. Das, D.; Arur, S. Conserved insulin signaling in the regulation of oocyte growth, development, and maturation. Mol. Reprod. Dev. 2017, 84, 444-459. [CrossRef] [PubMed]

42. Itami, N.; Munakata, Y.; Shirasuna, K.; Kuwayama, T.; Iwata, H. Promotion of glucose utilization by insulin enhances granulosa cell proliferation and developmental competence of porcine oocyte grown in vitro. Zygote 2017, 25, 65-74. [CrossRef] [PubMed]

43. Shafiee, M.N.; Seedhouse, C.; Mongan, N.; Chapman, C.; Deen, S.; Abu, J.; Atiomo, W. Up-regulation of genes involved in the insulin signalling pathway (IGF1, PTEN and IGFBP1) in the endometrium may link polycystic ovarian syndrome and endometrial cancer. Mol. Cell. Endocrinol. 2016, 424, 94-101. [CrossRef] [PubMed]

44. Wang, F.; Wang, S.; Zhang, Z.; Lin, Q.; Liu, Y.; Xiao, Y.; Xiao, K.; Wang, Z. Defective insulin signaling and the protective effects of dimethyldiguanide during follicular development in the ovaries of polycystic ovary syndrome. Mol. Med. Rep. 2017, 16, 8164-8170. [CrossRef] [PubMed]

45. Elis, S.; Desmarchais, A.; Maillard, V.; Uzbekova, S.; Monget, P.; Dupont, J. Cell proliferation and progesterone synthesis depend on lipid metabolism in bovine granulosa cells. Theriogenology 2015, 83, 840-853. [CrossRef]

46. Xing, Y.; Liu, Y.; Liu, X.; Wang, S.; Li, P.; Lin, X.; Sui, C.; Xu, C.; Qi, B.; Tong, Q. Effects of Gui Zhu Yi Kun formula on the P53/AMPK pathway of autophagy in granulosa cells of rats with polycystic ovary syndrome. Exp. Ther. Med. 2017, 13, 3567-3573. [CrossRef] [PubMed]

47. Yong, E.L.; Baird, D.T.; Yates, R.; Hillier, S.G.; Reichert, L.E. Hormonal regulation of the growth and steroidogenic function of human granulosa cells. J. Clin. Endocrinol. Metab. 1992, 74, 842-849. [CrossRef] [PubMed]

48. Conover, C.A.; Faessen, G.F.; Ilg, K.E.; Chandrasekher, Y.A.; Christiansen, M.; Overgaard, M.T.; Oxvig, C.; Giudice, L.C. Pregnancy-associated plasma protein-a is the insulin-like growth factor binding protein-4 protease secreted by human ovarian granulosa cells and is a marker of dominant follicle selection and the corpus luteum. Endocrinology 2001, 142, 2155-2158. [CrossRef]

49. Spicer, L.; Aad, P. Insulin-like growth factor (IGF) 2 stimulates steroidogenesis and mitosis of bovine granulosa cells through the IGF1 receptor: Role of follicle-stimulating hormone and IGF2 receptor1. Biol. Reprod. 2007, 77, 18-27. [CrossRef] 
50. Alemi Yahya, M.; Meisel Sharon, S.; Hantisteanu, S.; Hallak, M.; Werner, H.; Bruchim, I. The proliferative effect of dendritic cells in ovarian cancer and the relationship with the Igf signaling pathway. Harefuah 2019, 158, 30-34.

51. Ellis, R.J. The general concept of molecular chaperones. Philos. Trans. R Soc. Lond. B Biol. Sci. 1993, 339, 257-261. [PubMed]

52. Velázquez, M.M.; Alfaro, N.S.; Salvetti, N.R.; Stangaferro, M.L.; Rey, F.; Panzani, C.G.; Ortega, H.H. Levels of heat shock protein transcripts in normal follicles and ovarian follicular cysts. Reprod. Biol. 2011, 11, 276-283. [CrossRef]

53. Malumbres, M.; Barbacid, M. Cell cycle, CDKs and cancer: A changing paradigm. Nat. Rev. Cancer 2009, 9, 153-166. [CrossRef] [PubMed]

54. Hatzirodos, N.; Hummitzsch, K.; Irving-Rodgers, H.F.; Harland, M.L.; Morris, S.E.; Rodgers, R.J. Transcriptome profiling of granulosa cells from bovine ovarian follicles during atresia. BMC Genom. 2014, 15, 40.

(C) 2019 by the authors. Licensee MDPI, Basel, Switzerland. This article is an open access article distributed under the terms and conditions of the Creative Commons Attribution (CC BY) license (http://creativecommons.org/licenses/by/4.0/). 